\title{
Barriers in Utilization of Maternal Health Care Services: Perceptions of Rural Women in Eastern Nepal
}

\section{Lama S, Krishna AKI}

School of Public Health

SRM University

SRM Nagar, Kattankulathur-603203

Kancheepuram, Tamilnadu, India

\section{Corresponding Author}

Anil Kumar Indira Krishna

School of Public Health

SRM University

SRM Nagar, Kattankulathur-603203

Kancheepuram, Tamilnadu, India

Email: ikanilkrishna@gmail.com

\section{Citation}

Lama S, Krishna AKI. Barriers in Utilization of Maternal Health Care Services: Perceptions of Rural Women in Eastern Nepal. Kathmandu Univ Med J 2014;48(4):253-58

\begin{abstract}
Background

Nepal is promoting safe motherhood through maternity incentives schemes. Still about two-thirds of births take place at home. Inadequate access to health care and under utilization of services is the major reasons for poor health of women and children.
\end{abstract}

\section{Objectives}

The study aim to explore the barriers in utilization of maternal health care services in eastern Nepal specifically to explore the reasons for not availing the services and to assess the indigenous practices regarding maternal health.

\section{Methods}

An exploratory study design was adopted to elicit the information from the selected respondents from different villages. Focus group discussions and in-depth interviews were conducted. Data was transcribed and analyzed manually to identify themes.

\section{Results}

The barriers to maternal health care service utilization were identified as social factors like family pressure, superstition, shyness, misconception, negligence, illiteracy, alcoholism. Likewise, large family size, jobless, unnecessary expenditure on health services was identified as economic barrier. Some cultural practices were also found as barrier for not availing the health services.

\section{Conclusion}

The study explored factors that are contributing in not availing the maternal health care services. The elimination of these barriers will facilitate quality of care and health outcomes. Therefore, the interventions should be developed and implemented to improve the health status of women and children. The result of this study can be utilized to draw the attention of local government, in strategic planning related to maternal health interventions.

\section{KEY WORDS}

Barriers, indigenous practices, maternal health care services 


\section{INTRODUCTION}

Every year more than half million women die due to complications of pregnancy and childbirth. Almost $99 \%$ of maternal deaths occur in developing countries. Half of all maternal deaths occur in sub-Saharan Africa and another major portion in southern Asia. ${ }^{1}$ There were much variability between countries with a maternal mortality ratio of 240 deaths per 1,00,000 live births versus 16 deaths per 1,00,000 live births in countries of developed regions. ${ }^{2}$ Thus, maternal mortality continues to be a major public health problem.

Utilization of maternal health services vary from country to country and within the country itself in many developing countries. ${ }^{3}$ Access to health care services has a great deal of impacts on maternal and child survival and significantly affects mortality trends in a population. Antenatal care may play an indirect role in reducing maternal mortality by encouraging women to deliver with assistance of a skilled birth attendant or in a health facility. In most rural settings, there are challenges in increasing such health care service utilization mainly because the decisions that lead women to use the services seem to occur within the context of their marriage, household, and family. ${ }^{4}$

The situation is worse in developing countries due to inadequate access or poor utilization of health services. In Nepal, only $85 \%$ of women received antenatal check up, $35 \%$ undergoes institutional delivery and $51 \%$ use postnatal services. Maternal mortality ratio is 229 per $1,00,000$ live birth and neonatal mortality rate is 33 per 1000 live births. ${ }^{5}$ Complications of pregnancy and childbirth cause more death and disability than any other reproductive health problems. ${ }^{6}$ Examining the use of maternal health services in developing countries can inform programs about where to focus interventions that can reduce maternal and newborn mortality and improve their health outcomes. ${ }^{7}$ The study was conducted to explore the barriers in utilization of maternal health care services in Eastern Nepal.

\section{METHODS}

An exploratory research design was adopted to elicit information from the selected respondents from seven villages of Jhapa district from June to July 2012. The key informants of this study were pregnant women, postnatal mothers, mothers-in-law and service providers. The groups were divided according to service users, non-users and service providers. Six focus group discussions were conducted in different villages. Ten in-depth interviews were conducted with service providers in the health centers and women who delivered in home were interviewed in their home. Focus group discussions and in-depth interview guide were prepared according to the objective of the study and probing questions were asked for each of the main questions in order to make the participants clear and to make it easier for them to answer. Each focus group had about eight to ten participants which were scheduled for about one hour. Each discussion last about 50 to 60 minutes. Two people facilitated each focus group, in which one led the discussion and the other took down notes. All the sessions were recorded using digital voice recorders and field notes were taken for post discussion reference. The data was transcribed in local language and translated in English thereafter. Transcripts along with field notes were analyzed manually for key themes and sub themes through the use of thematic analysis. In addition, verbatim quotations were used to illustrate responses on issues and themes.

\section{RESULTS}

\section{Barriers in utilization of services}

\section{Users Perception on Social barriers}

Illiteracy and lack of awareness were perceived as barriers for not utilizing the maternal health care services. They believed most women from remote areas are illiterate and do not know the advantages of utilizing health care. One of the participants mentioned, "They do not visit health center because they are not aware of the services and its benefits for our health. Those women should be encouraged to visit health posts".

Some respondent felt that some women have misconception related to hospital delivery like fear of being operated and fear of being referred to higher centers. Besides this, superstition was also one of the barriers for not availing the services. One woman stated, "Sometimes they refer the patients to other private clinics saying that equipments needed are not enough in health post so it is difficult for women to manage to go there". Another woman mentioned, "It is difficult to find vehicle or any means of transportation, even ambulance is also not allowed during strike (no any vehicles are allowed to). Therefore we can't visit the health post even if we need and want to".

\section{Non-Users Perception on Social barriers}

Women's perception from this group was related to illiteracy and shyness; they said that it was shameful to go for check-up during pregnancy. They also had misconception related to medications provided during pregnancy. Women reported, "We have heard that taking medicines during pregnancy, including iron tablets causes nausea, leading to enlargement of the fetus resulting difficult delivery or even miscarriage". Other women stated, "I do not know how to read and write so I don't have any idea regarding the maternal care. My family says there is no benefit of going to health centers".

Women prefer to deliver in home as it was convenient for them. Women perceived shyness/ shame as the barrier. One woman stated, "I don't want to go to hospital as I don't want to be examined by male doctors because I feel uncomfortable to show my body parts". Women reported that most men in the community say that their wives do 
not need to go to hospital because their mother had never been to hospital even once. Women felt that since the society is male dominated their husband's decision have to be followed. No any health related problems were reported by women even though they gave birth at home.

The respondent felt that it was waste of time and money to go for postnatal check up. One woman said, "I know I should go to hospital for check up after delivery but baby was good he was feeding well, his activities were good too and I also don't have any problem so why should I go to hospital and increase unnecessary expenditure. If any complication happens then we will go".

\section{Perception of Service providers on social barriers}

Service providers also alleged that the main reasons for not availing the services are due to lack of awareness. A staff nurse stated, "Women often do not have enough time to visit a health facility due to social obligations and household chores".

\section{Users Perception on cultural barriers}

Some of the respondent felt that prevailing cultural practices leads to under utilization of health services. One woman stated that, "Most of the women in our village are forced to give birth in cow shed, often alone and stay there with baby afterwards for eleven days, we are bound to follow traditional and cultural practices". One woman said, "Nwaran" (name giving ceremony which forbids women from leaving the house or touching anyone for eleven days after delivery) so women are not able to go for health check up outside the home".

\section{Non-Users Perception on cultural barriers}

Women felt that it is important to follow their culture and tradition regarding home delivery especially for first baby. One of women stated, "There is a tradition in our family that first baby should be delivered at home so we cannot go against our family. We have a tradition that our elders will make decision for us and we respect it". While mentioning about cultural barriers post natal care, a woman stated, "It would be difficult to follow the practices like oil massage for mother and baby in hospital because of hospital rules".

\section{Perception of Service providers on cultural barriers}

The service providers also mentioned that there are various cultural practices because of the diverse people living in a community that are still being practiced in some community and those cultural practices prevent them from availing the health services. Female health volunteer stated, "Some prefer home delivery because of home environment (warmth from a fire, hot food and massage) some are reassured by elder women that their delivery can be managed at home, while some are too shy to seek care from a health facility, especially if they have to see a male health provider".

\section{Users Perception on economic barriers}

Unemployment was regarded as important barrier resulting in lack of money due to which decision is taken late, and the time taken to accumulate the assets delays care further which was the reason for the women from low economic status for not availing the services. One woman said, "Even though the services provided in health centers are free, the cost of transportation and other expenses are high, so people cannot afford to bear the extra costs. Therefore I think most of the women from remote villages are deprived of services because of lack of money".

One woman stated, "Government is providing financial assistance through maternity incentives to women seeking skilled delivery care in a health facility so no need to worry about the costs. It is all free so we have come for hospital delivery". But they also felt sometimes, health centers lack adequate facilities like X-ray, ultrasound scan, basic medicines. Therefore, they are referred outside. This leads to further expenses such as arrangement for transport. One woman said, "Delivering a child calls for lot of expenditures. People with less money cannot afford so they prefer to deliver at home. Although hospitals provide some money for check up and delivery, it is not enough. People cannot afford to pay the persons accompanying in hospital and other transportation expenses so the amount given by government is also not adequate at all to save poor people from the economic burden".

Postnatal mothers felt that once they get discharged, they have to visit again for checkups. For that, they cannot travel in local vehicle with newborn baby and mother so they have to hire private vehicle so it will cost more in travelling. If mother and baby are good then most of the women do not go for postnatal checkups.

\section{Non-Users Perception on economic barriers}

Some women did not attend antenatal clinic because they perceived pregnancy as normal phenomenon. The reason for not attending clinic was financial constrain. There are frequent instances of people having to sell their assets or borrow money, which often forced them to put their home or farm as collateral, to cover all the costs associated with seeking formal care. One woman said, "I know the services are free there but we can't afford to go there as we have to pay a lot of money for transportation." One woman stated, "There are altogether eight members in my family, and it is very difficult for me and my husband to look after the expenses like food, school and other. I do not want extra expenses by going to health canter which cost a lot to reach there since it is quite far from our place".

Men control important household decisions and money in most of the households. One woman stated, "Even if I want to go for check up for myself and baby, my husband does not think it is necessary to go as baby was feeding well and had no any other complications. Even though the services are free, cost to reach there is high. I do not want to put burden to my family. So whatever they say I have to obey". Once women deliver baby they perceived that everything is back to normal so women started their household chores. Therefore, women often did not have enough 
time to visit a health facility due to social obligations and household chores. One mother-in-law said, "Sometimes they recommend expensive investigations in case of complications which are not available in health post so we need to go to private clinics which cost more". This was also an important reason for utilization of postnatal care.

\section{Perception of Service providers on economic barriers}

Service providers mentioned that low economic status is not the barrier because the maternal health services they are providing are free of cost and some are of minimal cost.

\section{Indigenous practices}

Indigenous practices refer to the unique, traditional practices of the people in that particular area with respect to pregnancy and childbirth.

Some families believed that expectant women should not go out of home and cross the river. She should not make neighbors or relatives angry as they could become embittered killing her unborn child. In addition, pregnant women should not step over the plough and rope that is being tied to animals. Breaking these beliefs will result in prolonged and difficult delivery. So women are compelled to remain in home. Certain fruits are not given during pregnancy like papaya, pineapple, mango that leads early labour sometimes leading to abortion. Vitamins are also not given because they believe that vitamins are 'strengthening' so it will make the fetus grow big resulting in difficult delivery so women are encouraged to take some herbal preparations made at home.

Some families have the tradition that the first baby should be delivered at home. Home delivery is preferred because of convenience that provides homely environment and family support. A quiet, secluded room is chosen for delivery once labor pain starts. A large amount of straw an ideal insulation material is brought into the house to form the birth bed. After delivery it is burnt. In some villages, women are still forced to give birth in cow shed.

Postnatal confinement is commonly practiced in most of the villages in Nepal. Confinement is about keeping a mother and baby at home for a certain number of days or weeks. The tradition arose from the need to protect the newly born baby and mother from infection and help mother recover from the exhaustion of childbirth. During confinement, new mother and baby are given full body massage with mustard oil and allowed to sunbathe which encourages the shrinkage of the mother's womb. It is generally believed that after birth a mother's body loses "balance" and enters a "cold stage" due to the loss of blood. Food is therefore usually made with ingredients that are believed to be warming and hence speed up recovery from exhaustion of childbirth. Special soup is given to mother 'Jawano ko jhol' (thyme soup), 'chakku' (sweet made from jagaggery) which helps to increase milk secretion. Similarly, increased intake of ghee is believed to help regain strength and muscle repair. The confinement period is over after the rituals of
"Nwaran". This period of seclusion also functions as a rare opportunity for mother to rest.

Table 1. List of Open codes obtained on thematic analysis

\begin{tabular}{|l|c|l|}
\hline DOMAIN & CODES & CODE DESCRIPTION \\
\hline & B1 & Lack of education/illiteracy \\
\hline & B2 & Low socioeconomic status \\
\hline B3 & Family pressure \\
\hline B4 & Misconceptions \\
\hline Barriers & B5 & Shyness/shame \\
\hline B6 & Lack of transportation facilities \\
\hline B7 & No time \\
\hline B8 & Lack of awareness \\
\hline Economic barriers & B9 & Negligence \\
\hline & B11 & Cultural practices \\
\hline F1 & unemployment \\
\hline F4 & Large family \\
\hline & Health expenditure perceived as \\
\hline SB1 & Famile pressure \\
\hline Social barriers & SB2 & Misconceptions \\
\hline SB3 & Superstition \\
\hline SB4 & Negligence \\
\hline SBltural & Illiteracy \\
\hline SB7 & Shyness/ shame \\
\hline C1 & Religious practices \\
\hline A1 & Lack of formal education \\
\hline &
\end{tabular}

\section{DISCUSSION}

The pregnancy, delivery and postpartum periods are important in the women's life. The health care services that a woman receives during pregnancy, childbirth, and the immediate postnatal period are important for the survival and well-being of both the mother and the child. Various factors were perceived by the participants as barriers to maternal health service use. The 'barriers' identified are especially useful in explaining why the target area continues to have maternal and neonatal deaths. ${ }^{8}$

Most developing countries have achieved great success in extending the reach of antenatal care. ${ }^{7}$ Still there are barriers in availing the services. Travelling difficulties during pregnancy hinders women to use available care. Several other studies showed similar results in Malawi, ${ }^{8}$ Uganda, ${ }^{4}$ Vietnam, ${ }^{9}$ Cambodia, and Philippines. ${ }^{10}$ In the context of Nepal, transportation becomes worse during monsoon in damaged roads for the women to travel. There are very few local transportation facilities available in the villages, which limits their choices for travelling to the health centre. They are compelled to hire private vehicles that adds heavy economic burden to their livelihood. Studies from Jamaica found that an increased probability of early antenatal care attendance was associated with increased household expenditure. ${ }^{3}$ In contrast health care provider, do not perceive economic factor as a barrier but from the 
beneficiaries point of view free services are not facilitating them, as indirect cost like travelling to the health centre, food and accommodation of the people accompanying them becomes unaffordable which plays a vital role in late decision-making. Similar findings were revealed in study done in Vietnam, Nicaragua, Kenya. 9,11,12

Women from illiterate, rural and marginalized communities did not understand the importance of seeking routine care. Similar findings was there in Non-white South African women who did not see the value of antenatal care. ${ }^{3}$ The use of antenatal care services from skilled provider is strongly related to the education of mother. ${ }^{13,14}$ Many of the women viewed that they should only seek care once a complication occurs. Women believed that taking iron tablets during pregnancy cause enlargement of fetus leading to difficult delivery. They were not aware about the importance of the antenatal care thus women's education plays vital role in utilizing the services. ${ }^{15-17}$

Family and social restrictions affect women's care seeking behavior. $^{8}$ They believed that social norms discouraged women from seeking care, and women often did not have enough time to visit a health facility due to social obligations and household chores. They also felt that lack of support from family members restricted women's access to care. This was a commonly held view because they believed their daughters-in-law should deliver without medical attention, just as they themselves had done in the past. However, the scenario is different in Jamaica, women did not want to be treated as ill during uncomplicated pregnancies and so tended to delay initiation of antenatal care. ${ }^{3}$

Delivery care including giving birth in health centers and receiving skilled attendance at birth has a positive influence on the health of mothers and their children. The percentage of home delivery continues to remain high in all Southeast Asian countries except Vietnam. Bangladesh, Cambodia and Nepal having the highest levels of home deliveries. ${ }^{5}$ Nepal is promoting safe motherhood through initiatives such as providing financial assistance through maternity incentives schemes to women seeking skilled delivery care in a health facility. Still two-thirds of births (63 percent) take place at home. ${ }^{15}$

Women intended to give birth at health centers but they are reluctant to avail the service as they feel easy and convenient to deliver in home due to financial constrains and shyness. According to their perception most of the health care providers are male so they are not comfortable exposing their body parts for examination. Use of health facilities for delivery varies by women's socioeconomic status. Women perceived lack of money as reason for not going to hospital as many government health facilities are not able to treat complications, so they are referred outside. This leads to further expenses such as arrangement for transport even though incentives are provided for institutional delivery. Most of the populations in the rural areas are of low economic status that depends upon daily wages, so they cannot arrange funds immediately. In contrast, study done in Maharashtra India revealed socio-economic status is not the barrier. ${ }^{18}$ The study revealed that socio-economical and socio-cultural factors influenced women's decision-making about the place of delivery. They have to get the permission from their husband, ${ }^{19}$ and mother-in-law before seeking care even though they are responsible for the health status of their households.

In comparison to antenatal care and skilled attendance at birth, postnatal care has been largely neglected in safe motherhood programs. Postnatal complications is an important cause of maternal deaths in developing countries so it is highly recommended that women should receive at least three postnatal checkups. ${ }^{15}$ Some of the perceived barriers were lack of awareness and negligence. They feel that going to health centers was waste of money and time. They do not seek health services until and unless some complication arises. Moreover, cultural practice like name giving ceremony was also found as barrier.

Despite the fact that maternal health services are accessible to all villages in most instances at lower or no cost, people are not availing the services. The additional costs like transportation cost, investigation costs, and hospital stay expenses cost them higher than the free services provided. Many instances were given like being referred to the private hospital and clinics in case of complication that further add up their financial burden. In addition, women are not provided freedom for decision-making. Men made all the important household decisions and controlled the family's money. Some respondents felt that young women were incapable of taking important decisions. ${ }^{20}$ Some of the suggestions given by respondents in order to overcome such barriers are: increasing awareness among women and influencing members like husband, mother in laws, elderly women, upgrading health posts, providing training to health workers, empowering women in decision-making on how to take care of themselves.

\section{CONCLUSION}

Several factors are contributing in low utilization of maternal health care services. The government has made numerous efforts to improve maternal health. However, achievements are still low. Inadequate access to health care and under utilization of services is the major reasons for poor health of women and children. Therefore, it is important to explore the reasons for not availing the services. The elimination of barriers will facilitate quality of care and health outcomes. Hence, interventions should be developed and implemented to improve the barriers reported. The result of this study can be utilized to draw the attention of local government, in strategic planning related to maternal health interventions.

\section{ACKNOWLEDGEMENT}

The authors acknowledge the contribution of Dr. Vijay Gopichandran for manuscript editing, Jyoti Limbu and Aamod Dhoj Shrestha for data collection. 


\section{REFERENCES}

1. Ross JA, Campbell OMR, Bulatao R. The maternal and neonatal programme effort index (MNPI). Tropical medicine \& international health 2002;6(10):787-98.

2. World Health Organization (WHO).Trends in Maternal Mortality:1990 to 2008. 2012.

3. Say L, Raine R. A systematic review of inequalities in the use of maternal health care in developing countries: examining the scale of the problem and the importance of context. Bulletin of the World Health Organization 2007;85(10):812-9.

4. Parkhurst JO, Ssengooba F. Assessing access barriers to maternal health care: measuring bypassing to identify health centre needs in rural Uganda. Health Policy and Planning 2009;24(5):377-84.

5. Ministry of Health ans Population. Annual Report. Department of Health Services, Kathmandu, Nepal. 2010/2011.

6. Chakraborty N, Islam MA, Chowdhury RI, Bari W, Akhter HH. Determinants of the use of maternal health services in rural Bangladesh. Health Promotion International 2003;18(4):327-37.

7. Wenjuan Wang SASWaAF. Levels and Trends in the use of maternal health services in developing countries. 2011.

8. Kambala C, Morse T, Masangwi S, Mitunda P. Barriers to maternal health service use in Chikhwawa, Southern Malawi. Malawi Medical Journal 2011;23(1).

9. Oanh TTM. The Review of Barriers to Access Health Services for Selected groups in Vietnam: A case-study.

10. World Health Organization. Trends in maternal mortality: 1990 to 2008. Geneva: World Health Organization 2010.
11. Lubbock LA, Stephenson RB. Utilization of maternal health care services in the department of Matagalpa, Nicaragua. Revista Panamericana de Salud Publica 2008;24(2):75-84.

12. Fotso JC, Ezeh A, Oronje R. Provision and use of maternal health services among urban poor women in Kenya: what do we know and what can we do? Journal of Urban Health 2008;85(3):428-42.

13. Matsumura M, Gubhaju B. Women's status, household structure and the utilization of maternal health services in Nepal. Asia-Pacific Population Journal 2001;16(1):23-44.

14. Fan L, Habibov NN. Determinants of maternity health care utilization in Tajikistan: Learning from a national living standards survey. Health \& Place 2009;15(4):952-60.

15. Vanphanom Sychareun A, Phengsavanh VH. Cultural beliefs and traditional rituals about child birth practices in Lao PDR. Kuala Lumpur, Malaysia:: The Asian-Pacific Resource \& Research Centre for Women (ARROW).; 2009.

16. Kistiana S. Socio-Economic and demographic determinants of maternal health care utilization in Indonesia Faculty of Social Sciences, The Flinders University; 2009.

17. Mekonnen $Y$, Mekonnen A. Utilization of maternal health care services in Ethiopia. Calverton, Maryland, USA: ORC Macro 2002.

18. Griffiths P, Stephenson R. Understanding users perspectives of barriers to maternal health care use in Maharashtra, India. Journal of biosocial science 2001;33(03):339-59.

19. Strong A. An Examination of the Barriers to the Uptake of Healthcare Services During Pregnancy in Rural Tanzania. The Ohio State University; 2010.

20. Chorghade GP, Barker M, Kanade S, Fall CHD. Why are rural Indian women so thin? Findings from a village in Maharashtra. Public health nutrition 2006;9(1):9-18. 